\title{
Behavioral Modification Program (BMP): Role of Socio-Demographic Characteristics of Adult Drug Abusers in Saudi Arabia
}

\author{
Mahmoud Abdul Rahman Mahmoud ${ }^{1}$, Rashad Bin Mohammed Al-Sanousi², Siddig Ibrahim Abdelwahab²*
}

${ }^{1}$ College of Medicine, Al-Imam Mohammed Bin Saud Islamic University, Saudi Arabia

${ }^{2}$ Substance Abuse Research Centre, Jazan University, Jazan, Saudi Arabia

\begin{abstract}
This study shows a Behavior Modification Program (BMP) designed specifically to deal with adult drug abuser in Saudi Arabia. BMP involves multi-stage process in which successively more difficult behaviors are attained and maintained on reinforcement while drug-related behaviors are progressively reduced. The results of this program are compared against control group. Compared to control group, BMP group had higher mean age, more years of education and higher percentage of separated, divorced and widows. Only $27.7 \%$ of the study group and $44.5 \%$ of the control group were employed. The great majority of both groups were current smokers. $52.4 \%$ of study group had at least one co-morbid disease, compared to $30.3 \%$ in the control group $(P<0.001)$; they also had significantly higher rates of tuberculosis $(p=0.004)$, and anti-HCV $(p<0.001)$. The percentages of all drugs were higher among patients in the study group; amphetamine, cannabis, and alcohol had the highest percentage in both groups. Significant effects were achieved on all criteria over control group. The behavior modification approach described is offered as a viable alternative to traditional probation methods.
\end{abstract}

Keywords: Behavioral modification program; Socio-demography; Drug abuse; Saudi Arabia

\section{Introduction}

Addiction is the use of a substance, such as alcohol or another drug, to the point where a person develops a physical or psychological need for it. It is defined as repeated failures to refrain from drug use despite prior resolutions to do so $[1,2]$. Dependence is a state in which a person requires a steady concentration of a particular substance to avoid experiencing withdrawal symptoms. Addiction is a harmful habit that is out of control [3]. A wide range of substances can be abused. The most common classes include opioids, including such prescription pain killers as morphine and demerol, as well as illegal substances such as heroin; benzodiazapines and sedatives; stimulants; cannabinoid drugs as marijuana and hashish; cocaine-based drugs; hallucinogenic drugs; inhalants; alcoholic drinks; and cigarettes, cigars, and other tobacco products $[4,5]$.

Substance abuse is an enormous worldwide public health problem. The extent of worldwide psychoactive substance use is estimated at 2 billion alcohol users, 1.3 billion smokers and 185 million drug users [6]. The negative consequences of drug abuse affect not only individuals who abuse drugs but also their families and friends, various businesses, and government resources, although many of these effects cannot be quantified $[7,8]$. The most obvious effects of drug abuse include ill health, sickness and ultimately, death [9]. Treatment includes a spectrum of options representing differences in setting, types and range of services, and intensity of service use and delivery [10]. The goal of treatment is to place the patient in the appropriate level of care; that is, to provide the specific services needed by each patient, at the appropriate level of intensity, within the appropriate setting. It may involve outpatient treatment, intensive outpatient treatment, medically monitored intensive inpatient treatment, and medically managed intensive inpatient treatment. Treatment approaches include relapse prevention treatment, the matrix model, supportive-expressive psychotherapy, individualized drug counseling, motivational enhancement therapy, behavioral therapy for adolescents, multidimensional family therapy (MDFT) for adolescents, multisystemic therapy (MST), and combined approaches. The most common kinds of treatment programs include outpatient drug-free programs, long-term residential program, and short-term inpatient programs $[11,12]$. Cognitive-behavioral therapy
(CBT) is a type of counseling aimed at teaching the client how to become healthier and experience a more satisfying, fulfilling lifestyle by modifying certain thought and behavior patterns. It is based on the theory that thought and behavior can affect a person's symptoms and be an obstacle to recovery. CBT can be helpful in treating a variety of problems, including depression, anxiety and panic disorders, dealing with life event such as: death, divorce, disability, unemployment, issues with children and mounting stress $[13,14]$.

A behavioral modification program unit had been adopted in AlAmal hospital in Jeddah since its start in 1987. It is considered as one of the most crucial interventions undertaken in the treatment of drug abusers. In addition of being a topic of interest for the researcher, up to the researcher best knowledge, no assessment was done for the effect of admission in this unit on the prognosis of drug abusers. Estimation of proper length of stay in the unit will take a part. Therefore, the aim of this study was to participate in hospital program assessment and to share in decreasing the prevalence of relapse rate, through making recommendations regarding BMP treatment protocol; and to assess the prognosis of drug abusers admitted in the behavioral modification program unit at Al-Amal hospital in Jeddah governorate for one year. Finally, the study would help hospital administration in decisionmaking regarding the program protocol.

\section{Subjects and Methods}

\section{Study area and research design}

This study was done in the Jeddah governorate, in the Kingdom of Saudi Arabia. It is located in Al-Naeem district, one of the northern

*Corresponding author: Siddig Ibrahim Abdelwahab, Substance Abuse Research Centre, Jazan University, Jazan, Saudi Arabia, E-mail: siddigroa@yahoo.com

Received April 23, 2013; Accepted May 29 2013; Published June 04, 2013

Citation: Mahmoud MAR, Al-Sanousi RBM, Abdelwahab SI (2013) Behaviora Modification Program (BMP): Role of Socio-Demographic Characteristics of Adult Drug Abusers in Saudi Arabia. Clin Exp Pharmacol 3: 127. doi:10.4172/21611459.1000127

Copyright: (C) 2013 Mahmoud MAR, et al. This is an open-access article distributed under the terms of the Creative Commons Attribution License, which permits unrestricted use, distribution, and reproduction in any medium, provided the original author and source are credited. 
districts of Jeddah. A historical prospective record-based study design was used, where patients were identified from the records of Al-Amal Male Hospital. The study group consisted of those patients exposed to Behavioral Therapy Program (BMP). The treatment program used is a Modified Minnesota Program. BMP is the next step after detoxification treatment. It accepts those patients who are motivated for the longterm program. The program involves psychiatric, psychological, social, and spiritual counseling, as well as family therapy, in addition to sports activities and work therapy.

Sample characteristics: The study population includes addict male patients $(n=401)$ exposed to a similar treatment program. Those patients admitted to BMP who requested discharge during the orientation period, i.e. after 72 hours were excluded from the sample. The control group is a sample $(\mathrm{n}=336)$ from newly treated male adults addicts who were admitted to the same hospital during the same period and not involved in BMP. Sample size was calculated using PS-Power and Sample Size Calculation Software [15].

Data collection: A special form for data abstraction was generated and reviewed by experts for suitability and completeness. The form was designed to provide data to help in assessment of prognosis of BMP among drug abusers. The DSM-IV criteria were used regarding the main study outcome: sustained remission: abstinence for one-year forward [16].

Ethical considerations: The researcher took all the required steps for obtaining official permissions to access data (ethical approval No. 1424/21). No direct contact with patients took place as the study was record-based. Total confidentiality of any obtained information was secured. Any obtained information was only used for research purposes.

Statistical analysis: Data analysis was done using SPSS 20.0 statistical software package. Quality control was done at the stages of coding and data entry. Statistical description was done using frequencies, percentages for qualitative variables; and means $( \pm \mathrm{SD})$ for quantitative variables. Inferential statistical analysis was performed according to the characteristics of the data. Quantitative continuous data were compared using Student's t-test, ANOVA and nonparametric Kruskal-Wallis test. Qualitative variables were compared using Chi-square and Fisher exact tests. Statistical significance was considered at $\mathrm{p}$-value $<0.05$.

\section{Results}

Table 1 presents a comparison of the socio-demographic characteristics of patients in the study (BMP) and control groups. It indicates statistically significant differences between the two groups in all displayed data. As the table shows, the mean age of the control group was lower, 29.18 .0 years, compared to $31.9 \pm 8.4$ years in the study group. They had less years of education, compared to the study group, $8.5 \pm 3.2$ and $9.3 \pm 3.1$, respectively. As regards marital status, the study group had a higher percentage of separated, divorced and widows $(12.0 \%)$, compared to $4.1 \%$ in the control group. The two groups were also significantly different in their job status, where about one-fourth of the study group members were working $(27.7 \%)$, and compared to about half of the control group (44.5\%).

The smoking status of patients in the two groups is described in Table 2. It is evident that the great majority of both groups were current smokers, with no statistically significant difference. However, the mean number of smoking years was higher in the study group, and the difference was statistically significant $(\mathrm{P}<0.001)$.
Figure 1 displays a comparison of the presence of co-morbid physical conditions among patients in the study and control groups. It shows that more than half of BMP patients (52.4\%) had at least one comorbid physical condition, compared to less than one-third $(30.3 \%)$ of patients in the control group, and the difference was statistically significant $(\mathrm{P}<0.001)$.

Table 3 presents a comparison of the number and types of physical co-morbid physical conditions among patients in the study (BMP) and control groups. It points to statistically significant differences in the number of conditions, where $14.2 \%$ of the study group patients had more than one condition, compared to only $4.6 \%$ of those in the control group $(\mathrm{P}<0.001)$. Also, as regards the types of co-morbid physical conditions, BMP patients had statistically significantly higher rates of tuberculosis $(\mathrm{p}=0.004)$, and anti-HCV $(\mathrm{p}<0.001)$.

Table 4 illustrates the comparison of psychiatric co-morbid conditions among patients in the study (BMP) and control groups. It points to no statistically significant difference as regards the presence or absence of such conditions. However, the types of diagnoses showed a significant difference, where more patients in the control group had drug induced psychoses (20.2\%), compared to BMP patients (13.2\%), $\mathrm{p}=0.009$. Meanwhile, the history of suicidal attempts was higher among

\begin{tabular}{|c|c|c|c|c|c|c|}
\hline & \multicolumn{4}{|c|}{ Group } & \multirow{3}{*}{$X^{2}$} & \multirow{3}{*}{$\mathrm{p}$-value } \\
\hline & \multicolumn{2}{|c|}{ BMP $(n=401)$} & \multicolumn{2}{|c|}{ Control $(n=366)$} & & \\
\hline & No. & $\%$ & No. & $\%$ & & \\
\hline \multicolumn{7}{|l|}{ Age (years): } \\
\hline$<21$ & 29 & 7.2 & 28 & 7.7 & & \\
\hline $21-$ & 139 & 34.7 & 192 & 52.5 & & \\
\hline 30- & 152 & 37.9 & 102 & 27.9 & & \\
\hline $40+$ & 81 & 20.2 & 44 & 12.0 & & \\
\hline Range & \multicolumn{2}{|c|}{$18-63$} & \multicolumn{2}{|c|}{$18-64$} & & \\
\hline Mean \pm SD & \multicolumn{2}{|c|}{$31.9 \pm 8.4$} & \multicolumn{2}{|c|}{$29.1 \pm 8.0$} & $\mathrm{t}=4.61$ & $<0.001^{*}$ \\
\hline \multicolumn{7}{|l|}{$\begin{array}{l}\text { Total educational } \\
\text { years: }\end{array}$} \\
\hline$<6$ & 13 & 3.2 & 27 & 7.4 & & \\
\hline $6-9$ & 261 & 65.1 & 244 & 66.7 & 9.57 & $0.02^{*}$ \\
\hline $10-15$ & 94 & 23.4 & 76 & 20.8 & & \\
\hline \multicolumn{7}{|l|}{$16+$} \\
\hline Range & \multicolumn{2}{|c|}{$0-16$} & \multicolumn{2}{|c|}{$0-16$} & & \\
\hline Mean \pm SD & \multicolumn{2}{|c|}{$9.3 \pm 3.1$} & \multicolumn{2}{|c|}{$8.5 \pm 3.2$} & $t=3.48$ & $0.001^{*}$ \\
\hline \multicolumn{7}{|l|}{ Marital status: } \\
\hline Single & 252 & 62.8 & 246 & 67.2 & & \\
\hline Married & 101 & 25.2 & 105 & 28.7 & 15.87 & $<0.001^{*}$ \\
\hline $\begin{array}{l}\text { Divorced/separated/ } \\
\text { widow }\end{array}$ & 48 & 12.0 & 15 & 4.1 & & \\
\hline \multicolumn{7}{|l|}{ Current job: } \\
\hline Professional & 16 & 4.0 & 10 & 2.7 & & \\
\hline Clerical & 28 & 7.0 & 39 & 10.7 & & \\
\hline Skilled & 48 & 12.0 & 90 & 24.6 & & \\
\hline $\begin{array}{l}\text { Trade (self } \\
\text { business) }\end{array}$ & 18 & 4.5 & 24 & 6.6 & 33.59 & $<0.001^{*}$ \\
\hline $\begin{array}{l}\text { Never attended } \\
\text { a job }\end{array}$ & 27 & 6.8 & 23 & 6.3 & & \\
\hline Jobless & 257 & 64.3 & 171 & 46.7 & & \\
\hline Retired & 6 & 1.5 & 9 & 2.5 & & \\
\hline \multicolumn{7}{|l|}{ Job status: } \\
\hline Unemployed & 290 & 72.3 & 203 & 55.5 & & \\
\hline Working & 111 & 27.7 & 163 & 44.5 & 23.67 & $<0.001^{*}$ \\
\hline
\end{tabular}

(*) Statistically significant at $p<0.05$

Table 1: Comparison of the socio-demographic characteristics of patients in the study group (BMP) and control group. 


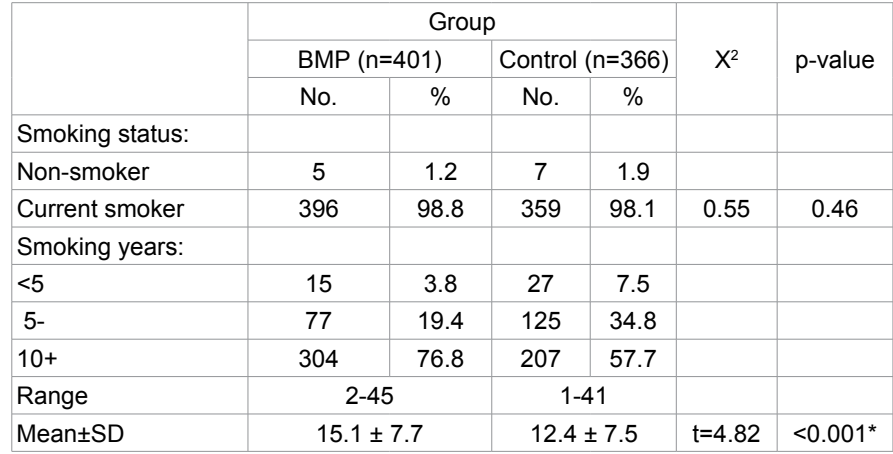

(*) Statistically significant at $p<0.05$

Table 2: Comparison of smoking among patients in the study group (BMP) and control group.

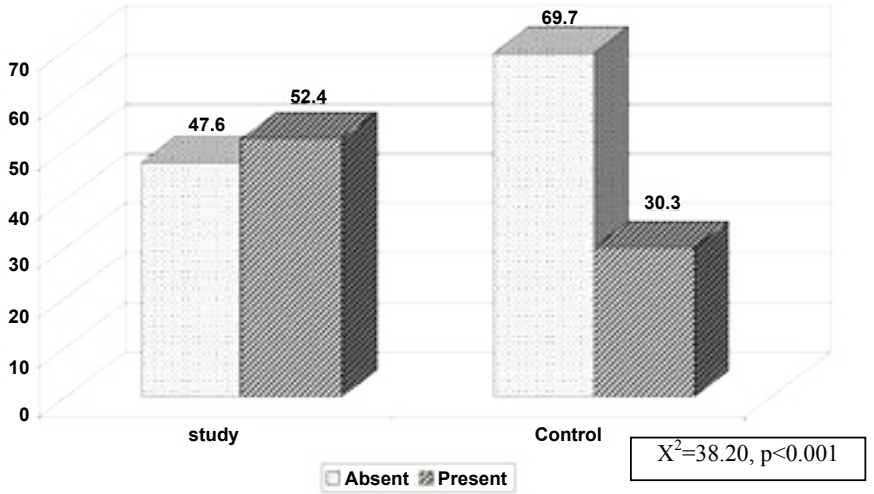

Figure 1: Co-morbid physical conditions among patients in the study (BMP) and control groups.

\begin{tabular}{|c|c|c|c|c|c|c|}
\hline & \multicolumn{4}{|c|}{ Group } & \multirow{3}{*}{$\mathrm{X}^{2}$} & \multirow{3}{*}{$p$-value } \\
\hline & \multicolumn{2}{|c|}{$\operatorname{BMP}(n=401)$} & \multicolumn{2}{|c|}{ Control $(n=366)$} & & \\
\hline & No. & $\%$ & No. & $\%$ & & \\
\hline \multicolumn{7}{|c|}{$\begin{array}{l}\text { Total co-morbid physical } \\
\text { conditions: }\end{array}$} \\
\hline 0 & 191 & 47.6 & 255 & 69.7 & & \\
\hline 1 & 153 & 38.2 & 94 & 25.7 & 43.39 & $<0.001^{*}$ \\
\hline $2-3$ & 57 & 14.2 & 17 & 4.6 & & \\
\hline \multicolumn{7}{|l|}{$\begin{array}{l}\text { Co-morbid physical } \\
\text { conditions:@ }\end{array}$} \\
\hline Hypertension & 5 & 1.2 & 3 & 0.8 & Fisher & 0.73 \\
\hline Diabetes mellitus & 17 & 4.2 & 12 & 3.3 & 0.49 & 0.49 \\
\hline Tuberculosis & 12 & 3.0 & 1 & 0.3 & 8.49 & $0.004^{*}$ \\
\hline Anti-HCV & 165 & 41.1 & 35 & 9.6 & 99.03 & $<0.001^{*}$ \\
\hline HBV & 13 & 3.2 & 18 & 4.9 & 1.39 & 0.24 \\
\hline HIV & 0 & 0.0 & 1 & 0.3 & Fisher & 0.48 \\
\hline Others & 61 & 15.2 & 60 & 16.4 & 0.20 & 0.65 \\
\hline
\end{tabular}

$\left({ }^{*}\right)$ Statistically significant at $p<0.05$

(@) Not mutually exclusive

Table 3: Comparison of co-morbid physical conditions among patients in the study group (BMP) and control group.

study group patients (2.5\%), compared to the control group $(0.5 \%)$, and the difference was statistically significant, $\mathrm{p}=0.03$.

\section{Discussion}

This study was carried out as a contribution to decrease the prevalence of relapse rate by making recommendations regarding BMP protocol. This was achieved through assessing the prognosis of drug abusers admitted in the Behavioral Modification Program (BMP) unit at Al-Amal hospital in Jeddah governorate for one year (2006). The sociodemographic characteristics of patients in the present study (Table 1) are similar to those reported in previous studies in the Kingdom. Thus, the mean age of both groups was around 30 years, which is close to the age reported in a study on addicts of heroin and alcohol in Jeddah [17]. The mean age of their study was 32.2 years, compared to 29.1 and 31.9 years in the control and study groups in our series. This is in fact the age where the addict would seek help to solve his problem after the age of adolescence and early adulthood, when the sequels of addiction are not still realized by him. In this regard, it has been claimed that increasing age is associated with more maturation and more seeking for solution of the addiction problem [18].

The levels of education of patients in our groups were also close to those previously reported. Thus, the mean years of education was around nine years, which corresponds to just a basic level of education (elementary and preparatory). Also, about two thirds of the present study patients completed 6 to 9 grades of education. A closely similar percentage was reported in KSA where $64 \%$ of their patients had completed 6-9 grades of education. On the same line, a study on addicts in Jeddah has mentioned that over $50 \%$ of drug users were without high school education [19]. These findings point to the untoward effects of drug addiction on education of the affected person, with subsequent negative effects on his future life, job opportunities, and career.

As regards marital status, about two thirds of the patients in the study and control groups of the current research were single. In congruence with this finding [17], have found that $66.7 \%$ of the addict patients in their study sample were single and divorced. Moreover, it has been reported that more than half of the drug users in their sample were single [19]. The finding is expected since the future of the addict person is jeopardized, and his chance of getting married is low, especially in conservative communities, where addiction is considered as a stigma. Also, in case the addict patient gets married, the physical, psychological, and financial problems associated with his problem would certainly lead to unstable marital life, which will soon end in divorce [20].

According to the present study findings, about three-fourth of the patients in study group, and more than half of those in the control

\begin{tabular}{|c|c|c|c|c|c|c|}
\hline & \multicolumn{4}{|c|}{ Group } & \multirow{3}{*}{$\mathrm{X}^{2}$} & \multirow{3}{*}{$\mathrm{p}$-value } \\
\hline & \multicolumn{2}{|c|}{$\operatorname{BMP}(n=401)$} & \multicolumn{2}{|c|}{ Control $(n=366)$} & & \\
\hline & No. & $\%$ & No. & $\%$ & & \\
\hline \multicolumn{7}{|l|}{$\begin{array}{l}\text { Co-morbid psychiatric } \\
\text { diagnoses: }\end{array}$} \\
\hline Absent & 308 & 76.8 & 262 & 71.6 & & \\
\hline Present & 93 & 23.2 & 104 & 28.4 & 2.74 & 0.10 \\
\hline \multicolumn{7}{|l|}{$\begin{array}{l}\text { Co-morbid psychiatric } \\
\text { diagnoses:@ }\end{array}$} \\
\hline Drug induced psychosis & 53 & 13.2 & 74 & 20.2 & 6.79 & $0.009^{*}$ \\
\hline Psychosis & 10 & 2.5 & 10 & 2.7 & 0.04 & 0.84 \\
\hline Drug induced mood disorder & 12 & 3.0 & 11 & 3.0 & 0.00 & 0.99 \\
\hline Mood disorder & 15 & 3.7 & 7 & 1.9 & 2.30 & 0.13 \\
\hline Other psychiatric disorders & 5 & 1.2 & 2 & 0.5 & 1.04 & 0.31 \\
\hline $\begin{array}{l}\text { Positive history of suicidal } \\
\text { attempt }\end{array}$ & 10 & 2.5 & 2 & 0.5 & 4.71 & $0.03^{*}$ \\
\hline
\end{tabular}

(*) Statistically significant at $p<0.05$

(@) Not mutually exclusive

Table 4: Comparison of co-morbid psychiatric conditions among patients in the study group (BMP) and control group. 
group were either jobless or had never attended a job. The finding related to the study group is in agreement with a study that reported that the majority (75.2\%) of their addict patients were jobless [17]. Meanwhile, the rate of unemployment in our control group is similar to that reported in a study in KSA, where more than half of the drug users were found to be unemployed [19]. Also, a rate of $26.4 \%$ of addicts who never attended a job has been reported in KSA [21]. This high rate of unemployment among addicts is quite plausible. It is attributed to their inability to commit themselves to any regular activity, along with their irresponsible behavior that makes them unable to sustain a job for a long time. Added to this is the high probability that they have not attained a level of education compatible with competitive jobs [22].

Concerning smoking, the present study has shown that the great majority of patients in both study and control groups were current smokers. Moreover, the number of smoking years was 12 to 15 years in the two groups, which mean that smoking started at early adolescence, given the mean age of these patients. These findings are in agreement with a Saudi study, which similarly demonstrated that ninety seven percent of his addict patients were smokers, and more than half of them had started smoking before the age of 15 years [23]. The association between smoking and addiction is well documented, and even some researchers have considered smoking as an addictive habit [24].

The present study has revealed that more than half of our study group, and about one third of our control group patients had at least one co-morbid physical condition, and the difference was statistically significant $(\mathrm{P}<0.001)$. These findings are incongruent with the figures reported in a hospital-based survey of substance dependence in the Kingdom of Saudi Arabia. In his study, it was found that $87 \%$ of the addict patients had some kind of physical disorder. This might be related to differences in drugs used [23].

The association between HCV and addiction is well documented. The prevalence of hepatitis $C$ virus antibodies was shown to be $60.5 \%$ among intravenous drug abusers, with a high risk of acquiring HCV infection. Intravenous drug use (IVDU) was found to be responsible for approximately $60 \%$ of the new cases of HCV infection $[25,26]$. Moreover, the prevalence of antibodies to hepatitis $\mathrm{C}$ virus (anti-HCV) in a population of IVDU in Jeddah, Kingdom of Saudi Arabia (KSA) was reported to be even higher $(74.6 \%)$, whereas the prevalence of anti- HCV in drug dependent patients who did not use the intravenous route was $10.5 \%$ [27].

As regards the types of co-morbid conditions, the most commonly encountered disorder in the present study was the presence of anti$\mathrm{HCV}$, which was found in more than two-fifth of BMP patients, and about one-tenth of the control ones, and the difference was statistically significant $(\mathrm{P}<0.001)$. These figures are lower than those reported in a KSA study where Hepatitis C Virus was detected in $69 \%$ of the patients [23]. This difference might be explained by the high percentage of intravenous injectors in that other study. Our figures are also lower than the figures mentioned in Jeddah, where the prevalence of hepatitis $\mathrm{C}$ virus infection amounted to $63.9 \%$ in drug addicts [21]. Conversely, a much lower prevalence of HCV antibodies was found among drug users in the Eastern Province of KSA, which was only 6.5\% [28]. The discrepancies among the various studies in the Kingdom might be explained by the different nationalities included in the various study samples, since many of the non-Saudi workers come from countries where the rate of HCV is high. They are also related to the types and modes of use of drugs [29]. On the other hand, the prevalence of hepatitis B virus, as a co-morbid physical condition among patients in the present study sample was relatively low, $3.2 \%$ and $4.9 \%$ in the study and control groups, respectively. The figures are quite close to those reported by in a study on the prevalence of Hepatitis $\mathrm{C}$ virus antibodies among intravenous drug abusers and prostitutes in Damascus, Syria. The rate of Hepatitis B virus was $5.3 \%$ among the intravenous drug abusers. The low rates of hepatitis $\mathrm{B}$, compared to Hepatitis $\mathrm{C}$ might be related to the decline of the rates of this disease following the institution of its vaccine in the early nineties [30].

According to the present study findings, about one-fourth of the patients in both study and control groups had some type of psychiatric co-morbid condition. The most commonly encountered disorder was drug induced psychoses (20.2\%), compared to BMP patients (13.2\%), $(\mathrm{P}=0.009)$. Meanwhile, the history of suicidal attempts was higher among study group patients $(2.5 \%)$, compared to the control group $(0.5 \%)$, and the difference was statistically significant, $\mathrm{p}=0.03$. These findings are in agreement with a national household survey of nicotine, alcohol, and drug dependence and psychiatric co-morbidity in the United Kingdom [31]. They have reported a lower rate of psychiatric co-morbidities $(12 \%)$ in the non-dependent population, compared with $22 \%$ of the nicotine-dependent, $30 \%$ of the alcohol-dependent, and $45 \%$ of the drug-dependent population. On the same line, it has been clarified that epidemiologic studies have shown that between 30 $60 \%$ of drug abusers have concurrent mental health diagnosis [32]. Meanwhile, in contradiction with the present study findings, it has been reported that only $4.5 \%$ of addict patients had mental disorders [23]. The differences might be related to the drugs used for addiction. In fact, some substances like cannabis, amphetamines, and alcohol are more likely to be associated with greater risks of co-morbid psychosis.

\section{Conclusion}

In the light of the study findings, it is concluded that addiction is associated with high levels of low education, unemployment, and smoking. The drugs mostly used were amphetamine, cannabis, and alcohol, and the age of start was around 20 years. Further prospective research is suggested, including OPD patients in addition to those hospitalized, with longer duration of follow-up to assess the return of the patient to the society and normal life years after remission, with focusing on various program components to assess their relative effectiveness. The current study faced some limitations which include (1) incomplete or unclear documentation in the medical files about some of the patients' data, (2) dropout of some patients from followup after discharge, with no data about their abstinence or relapse. The study represents only those admitted to the hospital and did not involve those attending OPD programs only.

\section{Acknowledgment}

Authors are very grateful to Al-Amal hospital in Jeddah governorate. Our appreciation is also extended for the help and fund received from Susbtance Abuse Research Centre, Jazan University, Saudi Arabia.

\section{References}

1. Rogers PJ, Smit HJ (2000) Food craving and food "addiction": a critical review of the evidence from a biopsychosocial perspective. Pharmacol Biochem Behav 66: 3-14.

2. Ahmed SH (2012) The science of making drug-addicted animals. Neuroscience 211: $107-125$.

3. Bell J (2012) Pharmacological Maintenance Treatments of Opiate Addiction $\mathrm{Br} J$ Clin Pharmacol.

4. Obembe S (2012) Practical Skills and Clinical Management of Alcoholism \& Drug Addiction, Elsevier.

5. Rush B, Martin G, Corea L, Rotondi NK (2012) Engaging stakeholders in review and recommendations for models of outcome monitoring for substance abuse treatment. Subst Use Misuse 47: 1293-1302. 
Citation: Mahmoud MAR, Al-Sanousi RBM, Abdelwahab SI (2013) Behavioral Modification Program (BMP): Role of Socio-Demographic Characteristics of Adult Drug Abusers in Saudi Arabia. Clin Exp Pharmacol 3: 127. doi:10.4172/2161-1459.1000127

6. Ho MK, Goldman D, Heinz A, Kaprio J, Kreek MJ, et al. (2010) Breaking barriers in the genomics and pharmacogenetics of drug addiction. Clin Pharmacol Ther 88: 779-791.

7. Lakhanpal P, Agnihotri AK (2007) Drug Abuse an International Problem: A short review with special reference to African Continent, Indian Journal of Forensic Medicine \& Toxicology 1: 1-11.

8. Kumpeer KL (1997) Drug Abuse Prevention What Works, DIANE Publishing.

9. Hall W (1994) Health and Psychological Effects of Cannabis Use, the, Current Issues Crim Just 6: 208.

10. Myers KM, Carlezon WA Jr (2010) Extinction of drug- and withdrawal-paired cues in animal models: relevance to the treatment of addiction. Neurosci Biobehav Rev 35: 285-302.

11. Classen CC, Spiegel D (2011) Supportive-Expressive Group Psychotherapy, Handbook of Psychotherapy in Cancer Care 105-117.

12. Milrod B (2009) Psychodynamic psychotherapy outcome for generalized anxiety disorder. Am J Psychiatry 166: 841-844.

13. Jackson C, Nissenson K, Cloitre M, Courtois C, Ford J (2009) Cognitivebehavioral therapy, Treating complex traumatic stress disorders: An evidencebased guide 243-263.

14. Khanna MS, Kendall PC (2010) Computer-assisted cognitive behavioral therapy for child anxiety: results of a randomized clinical trial. J Consult Clin Psychol 78: 737-745.

15. Lang IA, Galloway TS, Scarlett A, Henley WE, Depledge M, et al. (2008) Association of urinary bisphenol A concentration with medical disorders and laboratory abnormalities in adults. JAMA 300: 1303-1310

16. Witbrodt J, Romelsjö A (2012) Treatment seeking and subsequent 1-year drinking outcomes among treatment clients in Sweden and the U.S.A.: a crosscultural comparison. Addict Behav 37: 1122-1131.

17. El-Sheikh Sel-G, Bashir TZ (2004) High-risk relapse situations and self-efficacy: comparison between alcoholics and heroin addicts. Addict Behav 29: 753-758.

18. Ries RK, Miller SC, Fiellin DA, Saitz R (2009) Principles of addiction medicine, Lippincott Williams \& Wilkins.

19. Iqbal N (2001) Problems with inpatient drug users in Jeddah. Ann Saudi Med 21: $196-200$.

20. Power C, Rodgers B, Hope S (1999) Heavy alcohol consumption and marital status: disentangling the relationship in a national study of young adults. Addiction 94: 1477-1487.

21. Shawky S, Ghabrah TM, Abalkhail BA, Soliman NK (1999) Hepatitis C Infection among Drug Addicts, Saudi Medical Journal 20: 877-881.

22. Anglin MD, Booth MW, Ryan TM, Hser YI (1988) Ethnic differences in narcotics addiction. II. Chicano and Anglo addiction career patterns. Int J Addict 23 1011-1027.

23. Iqbal N (2000) Substance dependence. A hospital based survey. Saudi Med J 21: 51-57.

24. Kaminer Y, Bukstein O, Tarter RE (1991) The Teen-Addiction Severity Index rationale and reliability. Int J Addict 26: 219-226.

25. Laperche S, Le Marrec N, Simon N, Bouchardeau F, Defer C, et al. (2003) A new HCV core antigen assay based on disassociation of immune complexes: an alternative to molecular biology in the diagnosis of early $\mathrm{HCV}$ infection. Transfusion 43: 958-962.

26. Aarons E, Grant $P$, Soldan $K$, Luton $P$, Tang J, et al. (2004) Failure to diagnose recent hepatitis $C$ virus infections in London injecting drug users. J Med Virol 73: 548-553.

27. Njoh J, Zimmo S (1997) Prevalence of antibodies to hepatitis C virus in drugdependent patients in Jeddah, Saudi Arabia. East Afr Med J 74: 89-91.

28. Fathalla S, Al-Jama A, Badawy M, Sabry H, Awad O, et al. (1994) Prevalence of hepatitis $C$ virus infection in the Eastern Province of Saudi Arabia by REDNA second generation and supplemental EIA tests, Saudi medical journal 15: 281-285.

29. Oldfield III EC, Wallace MR, Hyams KC, Yousif AA, Lewis DE, et al. (1991) Endemic infectious diseases of the Middle East, Reviews of infectious diseases 199-217.

30. Othman BM, Monem FS (2002) Prevalence of hepatitis C virus antibodies among intravenous drug abusers and prostitutes in Damascus, Syria. Saudi Med J 23: 393-395.

31. Farrell M, Howes S, Bebbington $P$, Brugha $T$, Jenkins R, et al. (2001) Nicotine alcohol and drug dependence and psychiatric comorbidity Results of a national household survey, The British Journal of Psychiatry 179: 432-437.

32. Weller MP, Ang PC, Latimer-Sayer DT, Zachary A (1988) Drug abuse and mental illness. Lancet 1: 997. 